\title{
REVIEW
}

\section{CLINICAL MANIFESTATIONS OF DELIRIUM IN ELDERLY}

\author{
Liyana Najwa Inche Mat*, Wan Aliaa Wan Sulaiman*, Hoo Fan Kee*, Muhammad Afwan \\ Shamsul Baharin*, Surendran Ghenesan*, Siti Nabila Ishak*, Wan Fairuzlina Zainal Abidin*, Nor Liyana \\ Farhan Daud*, Tan Hong Yun*
}

*Department of Medicine Faculty of Medicine and Health Sciences University Putra Malaysia, Serdang, Malaysia

pISSN : 2407-6724 • eISSN : 2442-5001 • http://dx.doi.org/10.21776/ub.mnj.2018.004.02.6• MNJ.2018;4(2):78-85

- Received 14 November $2017 \bullet$ Reviewed 19 December $2017 \bullet$ Accepted 4 January 2018

\begin{abstract}
Delirium is commonly encountered in the elderly. It is important to recognize and subsequently treat delirium early to prevent morbidity and mortality. The primary objective of this article review is to gather specific information about each clinical manifestation of delirium in elderly. Sieving through numerous literature and studies regarding the topic of Delirium in the elderly. Majority of the article source were from Medline and PubMed as subscribed by the institution where there are more than 27 million citations in the field of biomedical articles. The articles include articles that was published in Malaysia and also international article due to the limitation in Malaysia itself. The articles were retrieved from publications in the year 1992 up to the current year 2017. Clinical manifestation of delirium that had been reviewed include disordered thinking, euphoric, language impairment, illusion, reversal of sleep wake cycle, inattention, disoriented and memory deficit. Most of the information is about prevalence, clinical diagnosis, and pathophysiology of each of the clinical manifestation. Delirium in elderly is very complex and complicated which involve physical, emotion feelings not only for the patient but also for people in their surroundings. Many articles reviewed explain about each of the symptoms in further details in term on how they act and how they interact with people surrounding.
\end{abstract}

Keywords: Delirium, elderly, clinical manifestations

Correspondence: liyananajwa@upm.edu.my 


\section{INTRODUCTION}

Delirium is a topic that was first described in over 2000 years ago. However, up until today it remains one of the topics that is poorly understood and recognized. ${ }^{1}$ Hence it is also a common disorder that is under diagnosed and not properly managed. ${ }^{2}$ According to Diagnostic and Statistical Manual of Mental Disorders (DSM-IV) delirium is defined as "a disturbance of consciousness that is accompanied by a change in cognition that cannot be better accounted for by a pre-existing or evolving dementia". This sudden drop in attention and cognition is common, serious and has a high risk for mortality especially in elderly people who are individuals over 65 years old. Inouye et al. reported that there has not been evidence of successful medical treatment or prevention for this condition and it have a potential to cause irreversible cognitive impairment. ${ }^{1}$ The prevalence of this condition has been under reported in local settings as there was no literature that can serves as evidence. However, the prevalence of delirium is on the rise due to the ageing population.

The thought of this disease process being complex and having multifactorial causes contributes to the cycle of underdiagnosed and poorly managed by health care provider. As an example of multifactor causes are the combination of demented patients with exposure to a sedative medication will elicit acute decline in cognitive functioning. ${ }^{3}$ Several major complications can arise as a result of under diagnosing this condition. ${ }^{4}$ As an example, it can cause prolong hospital admission which exposes patients to hospital acquired complications, increased mortality rate and poor physical and cognitive function. ${ }^{5,6,7}$

Therefore the main concern regarding the topic of delirium is identifying the sign and symptoms of the problem. According to Ryan et al. recognition technique must be applied specific to the symptoms notice by the patient, family member, nurses or general physician. ${ }^{8}$ The diagnosis of delirium is achieved in a situation where the patient match the definition and presents with disturbance of consciousness (i.e. inattention and reduce awareness of environment) and a change in cognition (i.e. memory deficit, language impairment and disorientation) as stated in DSMIV-TR. Thus in this effort the highlight of this review would be on the clinical manifestation of delirium in elderly. Problem on identifying the clinical presentation on delirium will be further elaborated in this review with the information regarding the prevalence of the symptoms.

The articles retrieved from previous studies can assist in identifying which clinical presentation appears more often compared to the others so that it will enable future care takers, family members and even patient to recognize these symptoms. Early recognition causes no delay in diagnosing the condition and thus results in better outcome. ${ }^{2}$

\section{METHODS}

This review article was conducted by sieving through numerous literature and studies regarding the topic of Delirium in the elderly. In the event that this topic is poorly understood, this paper aims to give enlightenment regarding the topic. As the title suggest that this is an umbrella topic where delirium can be viewed from different points and covers different aspects, this study focuses on a more specific aspect of the topic which is the clinical manifestation of delirium and its prevalence. Hence, our main goal is to provide a comprehensive review of the clinical manifestations of delirium in elderly and it's prevalence by analyzing various literatures, compiling and understanding each sign and symptoms presented in an elderly.

Several data sources were accessed in the process of retrieving previous studies. Majority of the article source were from Medline and PubMed as subscribed by the institution where there are more than 27 million citations in the field of biomedical articles. Other sources such as The Lancet, British Journal of Psychiatry, and Journal of American Geriatric Society were also used as a tool to collect the articles as there were journals covering vast array of topic regarding the human health. Efficiency of the article collecting process several key words were used to access literature that was accurate, concise and focused on the topic. These key words were derived from the clinical manifestation of delirium. Some of the searched term used are delirium, sleep-wake cycle, disordered thinking, emotional changes, language impairment, delusion, hallucinations, inattention, disorientated and memory deficit. An inclusion criterion was also determined to ensure 
that the articles fulfill the requirement before being analyzed. The literature must contain introduction regarding the clinical presentation of delirium, the epidemiology and prevalence of the symptom and sign and also the pathophysiology of the clinical manifestation. However, there were limited studies in Malaysia which included all the selection criteria, hence, international journals were also analyzed. Furthermore, the articles were retrieved from publications in the year 1992 up to the current year 2017. An average of 6 articles per subtopic of the clinical manifestation was found and only half conform to the inclusion criteria and analyzed.

\section{DISCUSSION}

\section{Disordered thinking}

Disordered thinking is one of the sign that can be seen in delirious patient. An elderly with delirium commonly presents with slow and irrational thinking. They always come out with incoherent idea and jumbled up thoughts. In diagnosing an elderly with delirium, Confusion Assessment Method (CAM) is one of the commonly used rating scales in identifying delirium. One of the criteria in this rating scale is disorganized thinking. Compared to dementia, delirious patient has disorganized thinking while in demented patients, their thought process will be limited. ${ }^{9,10}$ Apart from that, according to Conn and Lieff (2001) elderly with delirium presented with speech disturbances. They tend to choose inaccurate words in their speech. Mostly, their words are incorrect and inappropriate. Their context will be disjointed and limited. They also described their observation in delirious patient who are easily distracted, talk off the topic and having difficulty in focusing during interviews. They constantly repeat the words and frequently distracted with the environment. ${ }^{11}$

Furthermore, disordered thinking can be due to stroke, transient ischemic attack and brain injury. These causes of delirium lead to recent onset and concurrent neurological deficit. ${ }^{12}$ Boettger and Breitbart (2010) found that in conducting Memorial Delirium Assessment Scale (MDAS) items for 100 delirium cases, $100 \%$ of them either in hypoactive or hyperactive subtype were having disorganized thinking. However, $77.4 \%$ of hypoactive subtype and $78.7 \%$ of hyperactive subtype presented with moderate to severe in disorganized thinking. ${ }^{13}$

Through this study, the authors concluded that in both subtypes of delirium, cognitive impairment was the most prominent symptoms as it promote the severity of delirium within their sample cohort. These findings reached similarity to the findings of Meagher et al. According to their study, $54 \%$ of 100 patients had thought process abnormality and $22 \%$ were included in moderate to severe. ${ }^{14}$

\section{Disorientation}

According Dorland's Pocket Medical Dictionary 29th edition, disorientation is defined as a state of mental confusion as to time, place or identity. Patient will be unable to answer correctly the questions regarding the current year, where they are and whom they are talking to. It is one of the most important symptoms of delirium that tend to be missed if patients are not directly asked for the information. This symptom remains having the highest prevalence of occurrence among delirious patients over the years which can be proved by several studies. Choosing a starting point from 2009, a study that was conducted to compare the phenomenological differences between hypoactive and hyperactive delirium by using Memorial Delirium Assessment Scale (MDAS) among cancer patients was done and the result reveals that $100 \%$ out of 100 delirious patients have some degree of disorientation. Looking at the severity, unfortunately more than $85 \%$ of hypoactive and hyperactive delirious patients presented with moderate to severe disorientation as compared to mild disorientation. ${ }^{13}$

However, the result of this study was debatable as the sample size was small and the exclusion criteria did not include patients with cognitive deficits such as due to brain metastases. Another study was conducted in 2011 by using newer version of scale which was Delirium Rating Scale (DRS-R98) showed the same trend as the previous one whereby disorientation present in $99.2 \%$ of the adult group subjects and $97.4 \%$ of the adult group subjects. ${ }^{15}$ As compared to the previous one, this study used larger sample size whereby the subjects were admitted to various medicosurgical and emergency wards. However, this study also did not exclude patients with psychiatric diagnoses such as psychotic illness, 
mood disorder and anxiety disorder which can affect the results of the study. A more recent longitudinal study of delirium phenomenology among 100 palliative care patient in 2013 which used double assessment scales which were DRSR98 and Cognitive Test for Delirium (CTD) showed prevalence of $81 \%$ of disorientation in all visits with DRS-R98 and $69 \%$ in all visits with CTD. ${ }^{16}$ Even though this research showed lower prevalence of disorientation, but the percentage is still considered as significant as it was more than $50 \%$.

\section{Memory Deficit}

Memory is defined as the faculty by which sensations, impressions and ideas are stored and recalled. It can be classified into short-term memory and long-term memory. As compared to dementia which is progressive loss of memory in an alert person, memory deficits in delirium are more acute and it is also treatable. Delirium can present with short-term memory loss or longterm memory loss. The same studies as above have proved that it is one of the core symptoms of delirium. Looking at short term memory loss, the study in 2009 showed that short- term memory impairments presents in $100 \%$ of hypoactive and hyperactive delirium subjects. ${ }^{13}$

The next study that was conducted in 2011 revealed more than $94 \%$ prevalence of short-term memory loss in both adult and elderly group while the study in 2013 unveiled $81 \%$ memory loss among the patients. ${ }^{15,16}$ Interestingly, the prevalence of long-term memory loss are lower but showing an increasing trend. Unfortunately the study in 2009 was limited to only short-term memory impairment therefore, no data for longterm memory impairment available to compare with other studies. From the study in 2011, the prevalence of long-term memory loss were less than $54 \%$ in both groups while the study in 2013 showed higher prevalence which were $75 \%$.

\section{Language impairment}

Besides that, language impairment is one of the features that are categorized under criterion $\mathrm{C}$ in Diagnostic and Statistical Manual of Mental Disorders (DSM-5) for delirium. Language impairment is one of the cognition disturbances that occur in delirium apart from memory deficit, disorientation, visuospatial ability, or perception. Language impairment was previously referred under neuropsychiatric and behavioral symptoms but then classified into one of the key features under cognition disturbance in delirium. ${ }^{12,15}$ Based on the study of 100 adult cases of delirium, ${ }^{12}$ it is found that more than half of the delirious cases have language impairment which shows a significant trend in delirium cases, so it should to be taken into account while managing and treating the disease.

Table 1. Clinical manifestations of delirium and their features.

\begin{tabular}{|c|c|}
\hline $\begin{array}{l}\text { Clinical } \\
\text { manifestations of } \\
\text { delirium }\end{array}$ & Features \\
\hline Disordered thinking & $\begin{array}{l}\text { slow and irrational thinking; } \\
\text { incoherent idea and jumbled } \\
\text { up thoughts }\end{array}$ \\
\hline Disorientation & $\begin{array}{l}\text { unable to answer questions } \\
\text { regarding the current year, } \\
\text { where they are and whom } \\
\text { they are talking to }\end{array}$ \\
\hline Memory deficit & $\begin{array}{l}\text { acute short and long term } \\
\text { memory loss }\end{array}$ \\
\hline $\begin{array}{l}\text { Language } \\
\text { impairment }\end{array}$ & $\begin{array}{l}\text { one of the key features } \\
\text { under cognition disturbance } \\
\text { in delirium }\end{array}$ \\
\hline Emotional liability & $\begin{array}{l}\text { mood fluctuations; affective } \\
\text { disturbances }\end{array}$ \\
\hline $\begin{array}{l}\text { Disturbance of } \\
\text { sleep-wake cycle }\end{array}$ & $\begin{array}{l}\text { insomnia, sleep } \\
\text { fragmentation, daytime } \\
\text { somnolence, and reversal of } \\
\text { sleep-wake phases }\end{array}$ \\
\hline Inattention & $\begin{array}{l}\text { disturbance of attention and } \\
\text { alertness }\end{array}$ \\
\hline $\begin{array}{l}\text { Abnormal } \\
\text { perception }\end{array}$ & $\begin{array}{l}\text { illusions, hallucination and } \\
\text { delusion }\end{array}$ \\
\hline
\end{tabular}

\section{Emotional liability}

In elderly with delirium, their mood will fluctuate from time to time. Sometimes, they will be in a euphoric state but sometimes in depressed and angriness mood simultaneously. They also can become the most fearful person and their mood changes in a short period. Through observing the patient, affective disturbance, such as fear, anger, irritability, sadness, euphoria, or apathy might be present. Patients sometimes demonstrate abnormal behavior in the process of the interview. ${ }^{11}$ Patients describe their behavioral and emotional changes as an "emotional roller coaster". 
They may feel sad and depressed at one moment then recover from that situation, be relaxed at the next moment. Potential factor can be determined through interview such as acute grief reaction, for example in responding to questions on the death of a spouse. In order to determine if patient is in a depressed mood, other than observing their mood and facial expression, clinical presentation of insomnia, loss of appetite and withdrawal are evidence of depression. Precipitating factors of grief, chronic illnesses, stroke, physical disability and immobility and change in social circumstances are also common presentations of depression. ${ }^{12}$

\section{Disturbance of sleep wake cycle}

Sleep-wake cycle includes of about 16 hours of daytime wakefulness and 8 hours of night-time sleep which reflects the pattern of our 24 hours daily sleep. Our sleep-wake cycle is controlled by the body's circadian rhythm and sleep homeostasis. The suprachiasmatic nuclei (SCN) located in the anterior hypothalamus consist of a circadian pacemaker where the circadian rhythms are generated. Circadian rhythm abnormalities may be caused by a not functioning circadian timing system or some external environment modification. Sleep disturbances are usually found in mild and major neurocognitive disorders such as dementias and delirium. ${ }^{18}$ Disturbance of sleep-wake cycle is one of the symptoms listed in the DSM-III (Diagnostic and Statistical Manual of Mental Disorders III) diagnostic criteria. ${ }^{19}$

Patients with sleep disturbances may be presented with insomnia, sleep fragmentation, daytime somnolence, and reversal of sleep-wake phases. $^{20}$ However, environmental factors, psychoactive medications, surgery, age, pain, and other medical and neuropsychiatric conditions may alter the relationship between sleep and cognition. A research done by FitzGerald et al. used the Delirium Rating Scale-Revised-98 (DRSR98) to carry out the sleep assessment in delirium patients. This test assesses sleep-wake cycle disturbances where 0 for no disturbance, 1 for mild nocturnal sleep disturbance or occasional daytime drowsiness, 2 for moderate disorganization of sleep-wake cycle presented with daytime napping, episodes of nocturnal awakening and 3 for severe disruption of sleepwake cycle presented with day-night reversal of sleep-wake cycle or severe circadian disturbances with multiple episodes of sleep and wakefulness or severe sleeplessness. According to this study, moderate or greater sleep-wake disturbances has already associated with delirium rather than presented as an early sign of delirium. ${ }^{18}$ Severe sleep-wake cycle disturbances are strongly associated with delirium regardless of dementia status which is considered as the critical feature of delirium.

\section{Inattention}

Inattention is defined as inability to maintain attention to an external stimuli and inability to shift attention to a new stimuli. Disturbance of attention is also one of the symptoms listed in the DSM-III diagnostic criteria for delirium. ${ }^{19}$ According to Meagher et al. (2007), attention and comprehension are the aspects of cognition that best describe delirium. They also stated that delirium is a disorder of global cognition featured by a notable disturbance of attention and alertness. Researchers have suggested the use of some simple tests to screen for the essential features of delirium. Since inattention is one of the core symptoms of delirium, they are trying to find some brief and short tests which will be sensitive to delirium for this symptom. ${ }^{21}$ The simple tests that had been proposed by Voyer et al. (2016) are Serial Sevens Test (subtracting 7 from 100), Mini-Mental State Examination (MMSE), MTOYB (reciting the months of the year backward) and so on.

\section{Abnormal perception}

One of the clinical symptoms of delirium is abnormal perception which can be illusions, hallucination and delusion which lies under psychotic symptoms. Illusion is misperception of real external stimulus (occur when general level of sensory stimulation is reduced), hallucination is false sensory perception experienced without real external stimulus and delusions is false beliefs that cannot be corrected by logic and are not consistent with culture and education. Based on a study by Sandberg et al. (1999), a study on the psychotic symptoms among delirious and nondelirious elderly group, it shows that about $20.4 \%$ of delirious patient have delusions while only $7.2 \%$ have delusions in non-delirious patient. As for hallucination and illusion, $21.9 \%$ of delirious patient have it compared to only $3.7 \%$ in non-delirious patient. It shows a much significant 
of these psychotic symptoms in delirious patient compared to non-delirious patient. ${ }^{22}$

In another study by Meagher et al. (2007) regarding the relationship between cognitive and non-cognitive delirium symptoms which were conducted with a sample size of 100 adult cases of delirium, it shows that patient with psychosis had either perceptual disturbances (illusion or hallucinations) or delusions but not both. About $50 \%$ of the delirious cases have perceptual and thought disturbances and $31 \%$ have delusions of any severity but the number declines when referring to moderate and severe severity of perceptual and thought disturbances and delusions which is $26 \%$ and $9 \%$ respectively. In a study about delirium in elderly people, the result emphasizes that delirium is a clinical diagnosis and perceptual disturbances (hallucinations or illusions) and delusions is not one of the key diagnostic features for delirium but it is one of the supporting features. ${ }^{1}$

\section{CONCLUSION}

In conclusion, delirium in elderly is a very complex and complicated as it involves physical, emotion feelings not only for the patient themselves but also for people around them. Many articles reviewed explain about each of the symptoms in further details in terms of the patient act and how they interact with the surrounding environment. There is very limited research regarding the clinical manifestations delirium in elderly conducted in Malaysia setting. The researchers aspire that this review article may contribute to shed a light and also raise awareness on the subject matter.

\section{REFERENCES}

1. Inouye SK, Westendorp RG, Saczynski JS. Delirium in elderly people. Lancet [Internet]. 2014 Mar 8 [cited 2017 Nov 7];383(9920):911-22. Available from: http://www.ncbi.nlm.nih.gov/pubmed/2399 2774

2. Wass S, Webster PJ, Nair BR. Delirium in the elderly: a review. Oman Med J [Internet]. Oman Medical Specialty Board; 2008 Jul [cited 2017 Oct 29];23(3):150-7. Available from:

http://www.ncbi.nlm.nih.gov/pubmed/2235 9704
3. Johnson J, Sims R, Gottlieb G. Differential diagnosis of dementia, delirium and depression. Implications for drug therapy. Drugs Aging [Internet]. 1994 Dec [cited 2017 Nov 7];5(6):431-45. Available from: http://www.ncbi.nlm.nih.gov/pubmed/7858 369

4. Johnson JC. Delirium in the elderly. Emerg Med Clin North Am [Internet]. 1990 May [cited 2017 Nov 7];8(2):255-65. Available from:

http://www.ncbi.nlm.nih.gov/pubmed/2187 681

5. Witlox J, Eurelings LSM, de Jonghe JFM, Kalisvaart KJ, Eikelenboom P, van Gool WA. Delirium in Elderly Patients and the Risk of Postdischarge Mortality, Institutionalization, and Dementia. JAMA [Internet]. American Medical Association; 2010 Jul 28 [cited 2017 Nov 7];304(4):443. Available from: http://jama.jamanetwork.com/article.aspx?d oi=10.1001/jama.2010.1013

6. Agoes, A., Lestari, R., \& Alfaruqi, S. Effects of Brain Age to Increase Cognitive Function in Elderly. Malang Neurology Journal, 2(2), (2016). 64-70. doi:http://dx.doi.org/10.21776/ub.mnj.2016. 002.02.4

7. Sunarti, S., Rahayu, M., \& Desetyaputra, D. Geriatric Patient with Delirium Profile in Saiful Anwar General Hospital Malang from January 2005 until June 2010. Malang Neurology Journal, 1(2), (2015). 61-67. doi:http://dx.doi.org/10.21776/ub.mnj.2015. 001.02.3

8. Ryan DJ, O'Regan NA, Caoimh RÓ, Clare J, $\mathrm{O}^{\prime}$ Connor $\mathrm{M}$, Leonard $\mathrm{M}$, et al. Delirium in an adult acute hospital population: predictors, prevalence and detection. BMJ Open [Internet]. British Medical Journal Publishing Group; 2013 Jan 7 [cited 2017 Nov 7];3(1):e001772. Available from: http://www.ncbi.nlm.nih.gov/pubmed/2329 9110.

9. Mittal V, Muralee $S$, Williamson $D$, McEnerney $\mathrm{N}$, Thomas J, Cash $\mathrm{M}$, et al. Review: Delirium in the Elderly: A Comprehensive Review. Am J Alzheimer's Dis Other Dementiasr [Internet]. SAGE PublicationsSage CA: Los Angeles, CA; 2011 Mar 31 [cited 2017 Nov 7];26(2):97-109. Available 
http://journals.sagepub.com/doi/10.1177/15 33317510397331

10. Edlund $A$, Lundström $M$, Sandberg $O$, Bucht G, Brännström B, Gustafson Y. Symptom Profile of Delirium in Older People With and Without Dementia. J Geriatr Psychiatry Neurol [Internet]. Sage PublicationsSage CA: Los Angeles, CA; 2007 Sep 29 [cited $2017 \mathrm{Nov}$ 4];20(3):166-71. Available from: http://journals.sagepub.com/doi/10.1177/08 91988707303338

11. Conn DK, Lieff S. Diagnosing and managing delirium in the elderly. Can Fam Physician [Internet]. 2001 [cited 2017 Nov 4];47(1). Available from: http://www.cfp.ca/content/47/1/101.short

12. Khoo FRACGP $S$, Adventist Hospital P, Siew Beng K. Review Article Acute Grief with Delirium in an Elderly: Holistic Care. Malaysian Fam Physician [Internet]. 2011 [cited 2017 Nov 7];6:1985-207. Available from: http://emfp.org/issues/2011v6n2_3/pdf/delirium_in _elderly.pdf

13. Boettger S, Breitbart W. Phenomenology of the subtypes of delirium: Phenomenological differences between hyperactive and hypoactive delirium. Palliat Support Care [Internet]. Cambridge University Press; 2011 Jun 4 [cited 2017 Nov 4];9(2):129-35. Available from: http://www.journals.cambridge.org/abstract _S1478951510000672

14. Meagher DJ, Moran M, Raju B, Gibbons D, Donnelly S, Saunders J, et al. Phenomenology of delirium. Assessment of 100 adult cases using standardised measures. Br J Psychiatry [Internet]. The Royal College of Psychiatrists; 2007 Feb 1 [cited 2017 Nov 4];190(2):13541. Available from: http://www.ncbi.nlm.nih.gov/pubmed/1726 7930

15. Grover S, Agarwal M, Sharma A, Mattoo S, Avasthi A, Chakrabarti S, et al. Symptoms and Aetiology of Delirium: A Comparison of Elderly and Adult Patients 譫妄的症狀和病 原學 : 老年和成年患者的比較. East Asian Arch Psychiatry [Internet]. 2013 [cited 2017 Nov 4];23:56-64. Available from: https://search.proquest.com/openview/651 1eec6eb1ad4a347afddadc3fe5b3d/1?pqorigsite $=$ gscholar $\& \mathrm{cbl}=27817$
16. Leonard M, Adamis D, Saunders J, Trzepacz P, Meagher D. A longitudinal study of delirium phenomenology indicates widespread neural dysfunction. Palliat Support Care [Internet]. Cambridge University Press; 2015 Apr 4 [cited 2017 Nov 4];13(2):187-96. Available from: http://www.journals.cambridge.org/abstract _S147895151300093X

17. Association ED, Society AD. The DSM-5 criteria, level of arousal and delirium diagnosis: inclusiveness is safer. BMC Med [Internet]. BioMed Central; 2014 Dec 25 [cited 2017 Nov 7];12(1):141. Available from: http://bmcmedicine.biomedcentral.com/arti cles/10.1186/s12916-014-0141-2

18. FitzGerald JM, O'Regan N, Adamis D, Timmons S, Dunne CP, Trzepacz PT, et al. Sleep-wake cycle disturbances in elderly acute general medical inpatients: Longitudinal relationship to delirium and dementia. Alzheimer's Dement (Amsterdam, Netherlands) [Internet]. Elsevier; 2017 [cited 2017 Nov 7];7:61-8. Available from: http://www.ncbi.nlm.nih.gov/pubmed/2827 5701

19. Albert MS, Levkoff SE, Reilly C, Liptzin B, Pilgrim D, Cleary PD, et al. The Delirium Symptom Interview: An Interview for the Detection of Delirium Symptoms in Hospitalized Patients. Top Geriatr [Internet]. SAGE PublicationsSage CA: Los Angeles, CA; 1992 Jan 2 [cited 2017 Nov 4];5(1):14-21. Available from: http://journals.sagepub.com/doi/10.1177/00 2383099200500103

20. Watson PL, Ceriana P, Fanfulla F. Delirium: is sleep important? Best Pract Res Clin Anaesthesiol [Internet]. 2012 Sep [cited 2017 Nov 7];26(3):355-66. Available from: http://linkinghub.elsevier.com/retrieve/pii/S 1521689612000559

21. Voyer P, Champoux N, Desrosiers J, Landreville $\mathrm{P}$, Monette J, Savoie $\mathrm{M}$, et al. Assessment of inattention in the context of delirium screening: one size does not fit all! Int Psychogeriatrics [Internet]. Cambridge University Press; 2016 Aug 23 [cited 2017 Nov 7];28(8):1293-301. Available from: http://www.journals.cambridge.org/abstract _S1041610216000533

22. Sandberg O, Gustafson $Y$, Brännström B, Bucht $\mathrm{G}$. Clinical profile of delirium in older 
Clinical Manifestations of Delirium in Elderly

patients. J Am Geriatr Soc [Internet]. 1999

http://www.ncbi.nlm.nih.gov/pubmed/1057 Nov [cited 2017 Nov 7];47(11):1300-6.

Available

from: 